\section{Ophthalmological problems associated with preterm birth}

\begin{abstract}
As survival of preterm infants improves, the long-term care of consequent ophthalmic problems is an expanding field. Preterm birth can inflict a host of challenges on the developing ocular system, resulting in the visual manifestations of varied significance and pathological scope. The ophthalmic condition most commonly associated with preterm birth is retinopathy of prematurity, which has the potential to result in devastating vision loss. However, the visual compromise from increased incidence of refractive errors, strabismus, and cerebral vision impairment has significant impact on visual function, which also has influence on other developmental aspects including psychological and educational. In this review, the normal ocular development is discussed, aiming to exemplify the impact of early exteriorisation on one of the more naive organs of prematurity. This is then related to the incidence and visual consequences of many types of deficit, including refractive error, strabismus, and loss of visual function in preterm populations, with comparisons to term infant studies. Often these conditions are linked with causal and resultant factors being impossible to segregate, but the common factor of increased rates of all types of ophthalmic deficits demonstrates that children born prematurely are indeed premature for life.

Eye (2007) 21, 1254-1260; doi:10.1038/sj.eye.6702838
\end{abstract}

AR O'Connor,

Division of Orthoptics, University of Liverpool, Thompson Yates Building, Quadrangle, Brownlow Hill, Liverpool, L69 3GB, UK Tel: +44207040 8339; Fax: + 442070408494 . E-mail: a.fielder@ city.ac.uk

Received: 7 March 2007 Accepted in revised form: 21 March 2007

Keywords: low birth weight; prematurity; strabismus; ROP

\section{Introduction}

Improved neonatal care has resulted in the increased survival of preterm infants, ${ }^{1,2}$ but this reduced mortality can be associated with long-term medical sequelae. It is encouraging to
AR O'Connor ${ }^{1}$, CM Wilson ${ }^{2,3}$ and AR Fielder ${ }^{2,3}$

learn that the incidence of cerebral palsy in infants of very low birth weight (less than $1500 \mathrm{~g}$ and 32 weeks gestation) is falling in Europe ${ }^{3}$ although the actual number of children in the population with cerebral palsy is increasing because of increased survival. Preterm infants are at increased risk of chronic illnesses such as cerebral palsy and asthma, as well as having poor motor skills, poor adaptive functioning, and low intelligence quotient. ${ }^{4-7}$ In addition, cognitive deficits, behavioural, and emotional problems are also more prevalent in this population, which could cause or exacerbate the academic deficiencies. ${ }^{8-10}$

Ophthalmic challenges following preterm birth are numerous, and overall extremely low birth weight $(<1000 \mathrm{~g})$ infants are three times more likely to have a vision of less than 6/60 than those born at term. ${ }^{11}$ However, the impact of prematurity on long-term ophthalmic development is not confined to the smallest infants. ${ }^{12}$ Effects of prematurity on ocular and neurological development include retinopathy of prematurity (ROP), refractive error, strabismus, cerebral visual impairment, colour vision deficits, reduced contrast sensitivity (CS), visual field defects, and decreased visual acuity (VA). These factors will be discussed individually, while recognising that many are not independent of each other.

\section{Ocular development}

The preterm infant has a shortened intrauterine period and is therefore removed from an environment uniquely designed for protection, growth, and the appropriate stimulation of the fetus. In addition the exteriorised fetus, now the preterm neonate, is exposed to many abnormal environmental influences. While the light dose experienced by the retina of the preterm infant is related to postmenstrual age, ${ }^{13}$ this exposure to abnormal levels of light does not predispose infants to ROP. ${ }^{14}$ 
The British Association of Perinatal Medicine introduced the concept of a 'threshold of viability' for preterm births as being the period from 22 to 26 weeks gestational age (GA), which concurs with the survival rates in the EPICure study. ${ }^{15}$ Ocular development that occurs during and after this period and the subsequent damage caused by premature exteriorisation will be reviewed.

At term, the eyeball is relatively well developed compared to the rest of the body, and the most active stage of its development is between 6 months and term, time normally spent in utero. The gross structure of the globe becomes recognisable at approximately 7 weeks GA, and by threshold viability at 22 weeks GA many of the structures of the globe, such as the uveal tract and sclera, are near to full development. For example, the sclera is formed of 50 cell layers by 6 months GA, and no further mitoses are seen following this. However, the cornea, lens, retina, and macula have to develop further before term. The basic structure of the cornea is formed by 4 months GA: however, it undergoes structural change of flattening and increasing diameter just before term. The proportion of gamma crystalline in the lens increases throughout gestation, and the lens alters in shape from elongated to become spheroidal at term. Cell division ceases by 24 weeks GA yet retinal surface area doubles in size from 24 weeks GA until term. In addition to the development of individual structures, the overall eye size, as shown by in utero ultrasound investigations, increases significantly with growth spurts occurring at 16-20 weeks, 28-32 weeks, and finally after 37 weeks GA.

Table 1 Ocular dimensions in preterm population measured at 10-12 years of age ${ }^{26}$ compared to ocular dimensions in term population measured at 10 years of age $\mathrm{e}^{27}$

\begin{tabular}{lcr}
\hline & $\mathrm{O}^{\prime}$ Connor et $a l^{26}$ & Zadnik et $a l^{27}$ \\
\hline Corneal power (D) & $44.59(1.71)$ & $43.66(1.73)$ \\
Axial length (mm) & $22.47(0.99)$ & $23.31(0.83)$ \\
AC depth (mm) & $3.56(0.31)$ & $3.78(0.23)$ \\
Lens thickness (mm) & $3.50(0.18)$ & $3.42(0.15)$ \\
Vitreous depth (mm) & $15.41(0.92)$ & $16.11(0.83)$ \\
\hline
\end{tabular}

Transverse ocular diameter measurements showed $6 \mathrm{~mm}$ of growth between 22 and 38 weeks from 9.57 to $15.82 \mathrm{~mm}$ respectively. ${ }^{16}$ Ocular axial lengths increased $3.3 \mathrm{~mm}$ from 10.77 to $13.80 \mathrm{~mm}$ in the same time frame. ${ }^{17}$

The neural retina emerges around 26 days gestation, with the inner layer of the optic vesicle undergoing mitosis producing three or four compact layers of cells. ${ }^{18}$ Retinal development is centred around the putative macula and proceeds centroperipherally, ${ }^{19}$ with mitotic activity being gradually confined to the periphery until 24 weeks of gestation when all mitosis ceases. The retinal surface area is still expanding, but does so by growth and maturation of individual cells until 3 weeks after birth. ${ }^{19}$ Later, retinal growth is mainly in the periphery, the disc to macular distance remaining almost constant. ${ }^{20}$ Retinal vasculogenesis commences from the optic nerve head circumperipherally before 14 weeks GA, and is replaced at 21 weeks GA by angiogenesis, which is complete by term. There is a trend for an increase in the total vessel angle as the arcades develop through GAs. ${ }^{21}$

\section{Retinopathy of prematurity}

Population studies in England, ${ }^{22}$ Sweden, ${ }^{23}$ and New Zealand $^{24}$ show that ROP incidence, either mild or severe, for infants born at less than 1500-1700 $\mathrm{g}$ lies between 22 and $49 \%$. Although these epidemiological studies were undertaken about two decades ago, they provided the basis for subsequent detailed long-term outcome studies, which have attempted to differentiate the effects of preterm birth per se from both ROP and neurological insults. The sequelae of severe ROP have been well documented by the CRYO-ROP Study and more recently the ETROP Study; however, the purpose of this article is to consider the more subtle effects of prematurity, which include mild ROP.

\section{Refractive state}

It is well known that term infants are most commonly slightly hypermetropic. ${ }^{25}$ This type of hypermetropia is primarily axial with the reduction in hypermetropia

Table 2 Refractive outcomes in preterm population compared to term population

\begin{tabular}{|c|c|c|c|c|c|c|}
\hline & $\begin{array}{c}\text { Larsson term } \\
\text { controls }^{37}\end{array}$ & $\begin{array}{c}\text { Larsson } \\
\text { preterms }^{37}\end{array}$ & $O^{\prime} C_{0} n n r^{26}$ & Holmstrom $^{69}$ & Fledelius $^{70}$ & Darlow $^{48}$ \\
\hline Age of study population (years) & 10 & 10 & $10-12$ & 2.5 & 7-10 & $7-8$ \\
\hline Myopia \% (dioptres included) & $11.1(<0)$ & $15.2(<0)$ & $18.9(<0)$ & $10(<0)$ & $10.7(<-0.25)$ & $\mathrm{N} / \mathrm{R}(<0)$ \\
\hline Hypermetropia \% (dioptres included) & $0.9(>3)$ & $4.2(>3)$ & $6.6(\geqslant 3)$ & $4(>3)$ & $\mathrm{N} / \mathrm{R}$ & $18(>0)$ \\
\hline Astigmatism \% (dioptre cylinder) & $4.1(\geqslant 1)$ & $44(\geqslant 1)$ & $13.7(\geqslant 1)$ & $26(\geqslant 1)$ & $16(>0)$ & $11(>0)$ \\
\hline Anisometropia \% (dioptre difference in MSE R\&L) & $0.9(\geqslant 1)$ & $8.9(\geqslant 1)$ & $9(\geqslant 1)$ & $8.4(\geqslant 1)$ & $6(\geqslant 2)$ & $\mathrm{N} / \mathrm{R}$ \\
\hline
\end{tabular}

Abbreviations: N/R, not recorded; MSE, mean spherical equivalent. 
occurring over time through the process of emmetropisation. This results in the minimisation of ametropia in the presence of increasing axial length, flattening of the lens, and changes in other refractive components of the eye. Paradoxically, despite the shorter axial lengths, myopia is recognised to be associated with preterm birth, as illustrated in Tables 1 and 2 .

It is not only the vision around infancy and early school life that is affected by prematurity, the ametropic tendency continues through to adulthood. Table 1 compares at 10 years of age the differing ocular dimensions of axial length, corneal power, AC depth, lens thickness, and vitreous depth, which have all been shown to affect emmetropisation of preterm babies ${ }^{26}$ with those born at term. ${ }^{27}$

There are three classes of myopia associated with preterm birth. ${ }^{28}$ Firstly, infants born preterm are generally myopic before term, but this myopia may be the physiological norm at this stage of gestation and is secondary to a flat anterior chamber, increased corneal curvature, and a spherical lens. Corneal development is almost complete in utero by term and involves a rapid stage of corneal flattening and increasing corneal diameter from weeks 27 to 40 . In babies, exteriorised early corneal growth is compromised resulting in a cornea with higher refractive power. ${ }^{29}$ It has been postulated that the temperature deficit of $1.0-1.5^{\circ} \mathrm{C}$ these babies suffer contributes to this arrest of development. ${ }^{30}$

The lens becomes less spherical throughout gestation resulting in preterms having more spherical lenses (lens thickness $3.99 \mathrm{~mm}$ ) than term babies (lens thickness $3.76 \mathrm{~mm}$ ). ${ }^{31}$ The temporary physiological state of a short axial length undermines the usual correlation between axial length and refractive value. Thus, compared to full-term infants for the same post-menstrual age preterm infants have a shorter axial length, which is proportional to their gestational age. ${ }^{31}$

Preterm infants may develop myopia of prematurity (MOP), the second type of myopia of preterms, which is due to arrested development of the anterior segment and is irrespective of ROP status. The features of an eye with MOP are a low axial length to power ratio, a shallow anterior chamber, and a thick lens. ${ }^{32}$

The refractive status of children with mild ROP is similar to that of preterms without ROP but differs from children born at term. ${ }^{33}$ The third group are myopic secondary to severe $\mathrm{ROP}^{34,35}$ which may range from low to high myopia and is probably related to the disease process and not the treatment. In contrast to myopia not related to any aspect of prematurity, myopia following severe ROP is relatively stable in early childhood. ${ }^{36}$

A number of long-term studies have confirmed the increased incidence of myopia following preterm birth, but it is also important to recognise that the incidence of other refractive errors is also high, as shown in Table 2. In a population-based study of 293 low birth weight children who were assessed at 10-12 years of age, there was an increased incidence of myopia (mean spherical equivalent of $<0.0,9 \%$ ) and high hypermetropia (mean spherical equivalent of $\geqslant+3.0,6.6 \%) .{ }^{26}$ In contrast, the prevalence of myopia and hypermetropia for term births was 11.1 and $0.9 \% .{ }^{37}$ Increased astigmatism $(\geqslant 1 D C)$ of $13.7 \%$ and anisometropia ( $\geqslant 1 \mathrm{D}$ difference in mean spherical equivalent) of $9 \%$ in preterm populations has been found. ${ }^{26}$ In contrast the prevalence of anisoastigmatism and anisometropia in a populationbased sample of 6-year-old children of 1.0 and $0.6 \%$ respectively. ${ }^{38}$ Mild ROP does not impact refractive development with the exception of the risk of developing anisometropia, which is increased if any stage of ROP is present. ${ }^{39}$ Overall, refractive errors are four times more common in those born preterm $(29.6 \%)$ than those born at term $(7.8 \%){ }^{39}$

\section{Strabismus}

There is no disputing the increased prevalence of strabismus in the low birth weight population compared to children born at term, ${ }^{40-42}$ but the pattern of development and aetiology are less clear.

Most reports of strabismus in the low birth weight population combine all types of strabismus together, but ascertaining the precise classification reveals additional important information. For example, the ratio of esotropia : exotropia is $1: 1$ in the low birth weight population compared to $3: 1$ in the full-term children and $12 \%$ of the strabismus cases were classified as near exotropia, a relatively uncommon type of strabismus. ${ }^{41}$ As expected, a large number of cases of strabismus were associated with hypermetropia, but in addition there were many cases associated with myopia. These points indicate not simply an increase in the rate of strabismus in the low birth weight population but possibly a different aetiology compared to full terms, which may have implications for management.

The age at onset of strabismus in low birth weight children is variable, from the first few months of life to many years later. ${ }^{41,43-47}$ This variation has implications on the planning of long-term surveillance and care for low birth weight infants, in terms of when to assess the child. It would be beneficial if risk factors for the development of strabismus were identified, to minimise assessments required for maximum capture. The increased incidence of strabismus in children born prematurely has been attributed, either wholly or in part, to $\mathrm{ROP}_{r}^{43,48}$ increase in refractive error, ${ }^{49}$ and neurological impairment. ${ }^{44}$ However, these factors are inter-related and univariate analysis may simply be detecting 
confounding variables. This issue has been addressed in a number of studies by multifactorial analysis; however, the risk factors identified include cicatricial ROP, refractive error, family history, birth weight, anisometropia, maternal age, smoking, ethnic origin, and general development quotient, with all factors being independently associated with strabismus. ${ }^{41,42,44,50}$ This considerable disparity in risk factors highlights the complexity of identifying those children at greatest risk of developing strabismus.

While the aetiology of strabismus in general is not fully understood, the large increase in the prevalence in the preterm population may suggest a common aetiology. However, the previous risk factor analysis highlights the difficulty in determining any individual aetiological factor. One report of strabismus and other eye movement disorders has shown a reduction in the occipital brain volumes, ${ }^{51}$ which could also account for some of the changes in visual acuity, but further investigation in this area is needed.

It would not be surprising in the light of increased incidence of manifest deviation in the primary position that other ocular motility abnormalities also occur, but only one report has been found to include a more detailed ocular motility assessment in the nine positions of gaze. ${ }^{41}$ This report found a significant ocular motility disturbance in $3 \%$ of cases. Other reports of specific types of ocular motility disorders include one report of twins with double elevator palsy ${ }^{52}$ and another with three cases of benign opsoclonus, ${ }^{53}$ which spontaneously resolved. This small number of reports suggests that ocular motility assessment is not an essential component of a screening assessment.

\section{Visual functions}

So far the discussion has focused on the long-term effects of preterm birth on eye growth and eye movements, and at this juncture it is important to consider how visual functions might be affected.

\section{Visual acuity}

In children, it is important to measure acuity when development is complete; if tested before completion, it may not be possible to differentiate between a delay in development and an absolute deficit. However, early VEP deficits ${ }^{54}$ have been shown to persist and are confirmed by behavioural testing in later childhood ${ }^{48,55}$ and adult life $\mathrm{e}^{56}$ and this reduction applies to measurements at both near and distance. ${ }^{55}$

Although ROP and neurological damage can account for the majority of the severe cases of vision loss, the aetiology of the more subtle acuity deficits is unclear, with some cases of reduced VA not associated with any clinically identifiable cause $\mathrm{e}^{55}$ and independent of mild ROP. ${ }^{57}$ It has been speculated that prolonged exposure to illumination such as during treatment for jaundice may be implicated in the reduction of visual acuity, secondary to cone damage. ${ }^{58}$ Alternatively, it has been proposed that prenatal endotoxin exposure through intrauterine infections, which can be linked to preterm delivery, may be harmful to the developing retina and optic nerve potentially impacting on visual development. ${ }^{59}$

Neurological damage, including ischaemic brain lesions, may produce visual impairment in preterm children. ${ }^{60}$ In particular, intraventricular haemorrhage in the neonatal period has been reported to be associated with delayed grating and recognition acuity even when corrected for additional ophthalmic problems. ${ }^{61}$

At the severe end of the visual deficit spectrum stage 5 ROP, even after surgical intervention, low anatomical success rates result with only a very small proportion achieving measurable acuity. ${ }^{62}$

\section{Contrast sensitivity}

CS closely reflects functional ability, and deficits may be predictive of reading ability. ${ }^{63}$ This is important because it is known that the preterm population has an increase in specific reading difficulties; however, it has not been investigated whether these subtle deficits in CS contribute towards this. A reduction in CS has been reported in low birth weight children compared to those born at term ${ }^{5,64,65}$ and the deficit persists even in the absence of ROP or known neurological abnormalities. ${ }^{65}$ Although the magnitude of the reduction may be small (eg only $0.1 \log$ CS units, ${ }^{55}$ which is equivalent to two letters on the Pelli Robson chart), these deficits are not confined to just one spatial frequency. ${ }^{65}$ The functional relevance of this reduction remains to be determined.

\section{Visual fields}

Visual field deficits have been reported in preterm children in association with factors affecting both the retina and the visual pathway including treatment for $\mathrm{ROP}^{66}$ and neurological deficits such as intraventricular haemorrhage. ${ }^{61}$ Although the magnitude of these deficits is relatively small (eg a loss of $11^{\circ}$ on average following cryotherapy $^{66}$ or $15^{\circ}$ following laser treatment for $\mathrm{ROP}^{67}$ ), their impact on functional ability is unknown.

\section{Colour vision}

The CRYO-ROP study reported colour vision outcomes in children 5 and a half years of age and found a large increase of blue-yellow colour deficits, which was more 
than 200 times the rate found in the general adult population. The actual prevalence, however, was $2.8 \%$ for males and $2.2 \%$ for females, so is one of the less common deficits that occur in preterm children; however, as the CRYO-ROP study was not population-based, it may be inflating the actual prevalence of these deficits. With regard to the aetiology of the blue-yellow defect, the one factor they found on analysis that was related to the presence the blue-yellow defects was reduced visual acuity. However, they were not suggesting a causal link because the rate of blue-yellow defects in those with normal vision was still more than 100 times that of the general population. ${ }^{66}$

\section{Summary}

There is abundant evidence that children born prematurely are 'premature for life', with the visual system being affected in many ways along its course. Early exteriorisation not only removes the fetus from an environment uniquely suited to promote growth and protect it from harm, but exposes the preterm neonate to the risk of ocular and visual pathway damage. The consequences of these range from the subtle to severe, but it remains a truism that the post-natal weight gain of the baby's chart is a predictor of outcome. ${ }^{68}$

\section{References}

1 Cooke RW. Preterm mortality and morbidity over 25 years. Arch Dis Child Fetal Neonatal Ed 2006; 91(4): F293-F294.

2 Richardson DK, Gray JE, Gortmaker SL, Goldmann DA, Pursley DM, McCormick MC. Declining severity adjusted mortality: evidence of improving neonatal intensive care. Pediatrics 1998; 102(4 Part 1): 893-899.

3 Platt MJ, Cans C, Johnson A, Surman G, Topp M, Torrioli MG et al. Trends in cerebral palsy among infants of very low birthweight $(<1500 \mathrm{~g})$ or born prematurely ( $<32$ weeks) in 16 European centres: a database study. Lancet 2007; 369(9555): 43-50.

4 Vohr BR, Wright LL, Dusick AM, Mele L, Verter J, Steichen JJ et al. Neurodevelopmental and functional outcomes of extremely low birth weight infants in the National Institute of Child Health and Human Development Neonatal Research Network, 1993-1994. Pediatrics 2000; 105(6): 1216-1226.

5 Casey PH, Whiteside-Mansell L, Barrett K, Bradley RH, Gargus R. Impact of prenatal and/or postnatal growth problems in low birth weight preterm infants on school-age outcomes: an 8-year longitudinal evaluation. Pediatrics 2006; 118(3): 1078-1086.

6 Hack M, Flannery DJ, Schluchter M, Cartar L, Borawski E, Klein N. Outcomes in young adulthood for very-low-birthweight infants. N Engl J Med 2002; 346(3): 149-157.

7 Jaakkola JJ, Ahmed P, Ieromnimon A, Goepfert P, Laiou E, Quansah $\mathrm{R}$ et al. Preterm delivery and asthma: a systematic review and meta-analysis. J Allergy Clin Immunol 2006; 118(4): 823-830.
8 Reijneveld SA, de Kleine MJ, van Baar AL, Kollee LA, Verhaak CM, Verhulst FC et al. Behavioural and emotional problems in very preterm and very low birthweight infants at age 5 years. Arch Dis Child Fetal Neonatal Ed 2006; 91(6): F423-F428.

9 Dahl LB, Kaaresen PI, Tunby J, Handegard BH, Kvernmo S, Ronning JA. Emotional, behavioral, social, and academic outcomes in adolescents born with very low birth weight. Pediatrics 2006; 118(2): e449-e459.

10 Hack M, Youngstrom EA, Cartar L, Schluchter M, Taylor HG, Flannery D et al. Behavioral outcomes and evidence of psychopathology among very low birth weight infants at age 20 years. Pediatrics 2004; 114(4): 932-940.

11 Hack M, Taylor HG, Drotar D, Schluchter M, Cartar L, Andreias L et al. Chronic conditions, functional limitations, and special health care needs of school-aged children born with extremely low-birth-weight in the 1990s. JAMA 2005; 294(3): 318-325.

12 Robaei D, Kifley A, Gole GA, Mitchell P. The impact of modest prematurity on visual function at age 6 years: findings from a population-based study. Arch Ophthalmol 2006; 124(6): 871-877.

13 Robinson J, Moseley MJ, Thompson JR, Fielder AR. Eyelid opening in preterm neonates. Arch Dis Child 1989; 64(7 Spec No): 943-948.

14 Reynolds JD, Hardy RJ, Kennedy KA, Spencer R, van Heuven WAJ, Fielder AR. Lack of efficacy of light reduction in preventing retinopathy of prematurity. N Engl J Med 1998; 338(22): 1572-1576.

15 Costeloe K, Hennessy E, Gibson AT, Marlow N, Wilkinson AR. The EPICure study: outcomes to discharge from hospital for infants born at the threshold of viability. Pediatrics 2000; 106(4): 659-671.

16 Birnholz JC. Ultrasonic fetal ophthalmology. Early Hum Dev 1985; 12: 199-209.

17 Achiron R, Kreiser D, Achiron A. Axial growth of the fetal eye and evaluation of the hyaloid artery: in utero ultrasonographic study. Prenat Diagn 2000; 20(11): 894-899.

18 Hittner HM, Rhodes LM, McPherson AR. Anterior segment abnormalities in cicatricial retinopathy of prematurity. Ophthalmology 1979; 86(5): 803-816.

19 Provis JM, van Driel D, Billson FA, Russell P. Development of the human retina: patterns of cell distribution and redistribution in the ganglion cell layer. J Comp Neurol 1985; 233(4): 429-451.

20 De Silva DJ, Cocker KD, Lau G, Clay ST, Fielder AR, Moseley MJ. Optic disk size and optic disk-to-fovea distance in preterm and full-term infants. Invest Ophthalmol Vis Sci 2006; 47(11): 4683-4686.

21 Wilson C, Theodorou M, Cocker KD, Fielder AR. The temporal retinal vessel angle and infants born preterm. $\mathrm{Br} \mathrm{J}$ Ophthalmol 2006; 90(6): 702-704.

$22 \mathrm{Ng}$ YK, Fielder AR, Shaw DE, Levene MI. Epidemiology of retinopathy of prematurity. Lancet 1988; 2(8622): 1235-1238.

23 Holmstrom G, el Azazi M, Jacobson L, Sachs D, Sule J, Lennerstrand G. Epidemiology of ROP in the Stockholm area of Sweden. Acta Opthalmol 1993; 210(Suppl): 44-47.

24 Darlow BA. Incidence of ROP in New Zealand. Arch Dis Child 1988; 63: 1083-1086.

25 Cook RC, Glasscock RE. Refractive and ocular findings in the newborn. Am J Ophthalmol 1951; 34(10): 1407-1413.

26 O'Connor AR, Stephenson TJ, Johnson A, Tobin MJ, Ratib S, Fielder AR. Change of refractive state and eye size in 
children of birth weight less than $1701 \mathrm{~g} . \mathrm{Br} J$ Ophthalmol 2006; 90(4): 456-460.

27 Zadnik K, Mutti DO, Friedman NE, Adams AJ. Initial cross-sectional results from the Orinda longitudinal study of myopia. Optom Vis Sci 1993; 70(9): 750-758.

28 Fielder AR, Quinn GE. Myopia of prematurity: nature, nurture, or disease? Br J Ophthalmol 1997; 81(1): 2-3.

29 Donzis PB, Insler MS, Gordon RA. Corneal curvatures in premature infants. Am J Ophthalmol 1984; 98(5): 627-628.

30 Fielder AR, Levene MI, Russell-Eggitt IM, Weale RA. Temperature - a factor in ocular development? Dev Med Child Neurol 1986; 28: 279-284.

31 Fledelius HC. Pre-term delivery and the growth of the eye An oculometric study of eye size around term-time.. Acta Ophthalmol 1992 Suppl) 204: 10-15.

32 Fledelius HC. Ophthalmic changes from age of 10 to 18 years. A longitudinal study of sequels to low birth weight II. Visual acuity. Acta Ophthalmol (Copenh) 1981; 59(1): 64-70.

33 Quinn GE, Dobson V, Kivlin J, Kaufman LM, Repka MX, Reynolds JD et al. Prevalence of myopia between 3 months and $5 \frac{1}{2}$ years in preterm infants with and without retinopathy of prematurity. Ophthalmology 1998; 105(7): 1292-1300.

34 O'Connor AR, Stephenson TJ, Johnson A, Tobin MJ, Ratib S, Fielder AR. Change of refractive state and eye size in children of birth weight less than $1701 \mathrm{~g}$. Br J Ophthalmol 2006; 90(4): 456-460.

35 The natural ocular outcome of premature birth and retinopathy. Status at 1 year Cryotherapy for Retinopathy of Prematurity Cooperative Group. Arch Ophthalmol 1994; 112(7): 903-912.

36 Quinn GE, Dobson V, Repka MX, Reynolds J, Kivlin J, Davis B et al. Development of myopia in infants with birth weights less than 1251 grams. Ophthalmology 1992; 99(3): 329-340.

37 Larsson EK, Rydberg AC, Holmstrom GE. A populationbased study of the refractive outcome in 10-year-old preterm and full-term children. Arch Ophthalmol 2003; 121(10): 1430-1436.

38 Huynh SC, Wang XY, Ip J, Robaei D, Kifley A, Rose KA et al. Prevalence and associations of anisometropia and anisoastigmatism in a population based sample of 6 year old children. Br J Ophthalmol 2006; 90(5): 597-601.

39 O'Connor AR, Stephenson TJ, Johnson A, Tobin MJ, Ratib S, Moseley $\mathrm{M}$ et al. Visual function in low birthweight children. Br J Ophthalmol 2004; 88(9): 1149-1153.

40 Holmstrom G, Rydberg A, Larsson E. Prevalence and development of strabismus in 10-year-old premature children: a population-based study. J Pediatr Ophthalmol Strabismus 2006; 43(6): 346-352.

41 O'Connor AR, Stephenson TJ, Johnson A, Tobin MJ, Ratib S, Fielder AR. Strabismus in children of birth weight less than 1701 g. Arch Ophthalmol 2002; 120(6): 767-773.

42 Pennefather PM, Clarke MP, Strong NP, Cottrell DG, Dutton J, Tin W. Risk factors for strabismus in children born before 32 weeks' gestation. Br J Ophthalmol 1999; 83: 514-518.

43 Bremer DL, Palmer EA, Fellows RR, Baker JD, Hardy RJ Tung B et al. Strabismus in premature infants in the first year of life. Arch Ophthalmol 1998; 116: 329-333.

44 Holmstrom G, el Azzazi M, Kugelberg U. Ophthalmological follow up of preterm infants: a population based, prospective study of visual acuity and strabismus. $\mathrm{Br} \mathrm{J}$ Ophthalmol 1999; 83(2): 143-150.
45 Pott JWR, Sprunger DT, Helveston EM. Infantile esotropia in very low birth weight children. Strabismus 1999; 7(2): 97-102.

46 Schalij-Delfos NE, de Graaf MEL, Treffers WF, Engel J, Cats BP. Long term follow up of premature infants: detection of strabismus, amblyopia, and refractive errors. Br J Ophthalmol 2000; 84: 963-967.

47 Cooke RW, Foulder-Hughes L, Newsham D, Clarke D. Ophthalmic impairment at 7 years of age in children born very preterm. Arch Dis Child Fetal Neonatal Ed 2004; 89(3): F249-53.

48 Darlow BA, Clemett RS, Horwood J, Mogridge N. Prospective study of New Zealand infants with birth weight less than $1500 \mathrm{~g}$ and screened for ROP: visual outcome at age 7-8 years. Br J Ophthalmol 1997; 81: 935-940.

49 Kushner BJ. Strabismus and amblyopia associated with regressed ROP. Arch Ophthalmol 1982; 100: 256-261.

50 Chew E, Remaley NA, Tamboli A, Zhao J, Podgor MJ, Klebanoff M. Risk factors for esotropia and exotropia. Arch Ophthalmol 1994; 112: 1349-1354.

51 Shah DK, Guinane C, August P, Austin NC, Woodward LJ, Thompson DK et al. Reduced occipital regional volumes at term predict impaired visual function in early childhood in very low birth weight infants. Invest Ophthalmol Vis Sci 2006; 47(8): 3366-3373.

52 Bell JA, Fielder AR, Viney S. Congenital double elevator palsy in identical twins. J Clin Neuroophthalmol 1990; 10(1): 32-34.

53 Morad Y, Benyamini OG, Avni I. Benign opsoclonus in preterm infants. Pediatr Neurol 2004; 31(4): 275-278.

54 Birch EE, O'Connor AR. Preterm birth and visual development. Semin Neonatol 2001; 6(6): 487-497.

55 O'Connor AR, Stephenson TJ, Johnson A, Tobin MJ, Ratib S, Moseley $\mathrm{M}$ et al. Visual function in low birthweight children. Br J Ophthalmol 2004; 88(9): 1149-1153.

56 Fledelius HC. Ophthalmic changes from age of 10 to 18 years. A longitudinal study of sequels to low birth weight. II. Visual acuity. Acta Ophthalmol (Copenh) 1981; 59(1): 64-70.

57 O'Connor AR, Stephenson T, Johnson A, Tobin MJ, Moseley MJ, Ratib S et al. Long-term ophthalmic outcome of low birth weight children with and without retinopathy of prematurity. Pediatrics 2002; 109(1): 12-18.

58 Abramov I, Hainline L, Lemerise E, Brown AK. Changes in visual functions of children exposed as infants to prolonged illumination. J Am Optom Assoc 1985; 56(8): 614-619.

59 Loeliger M, Duncan J, Cock M, Harding R, Rees S. Vulnerability of dopaminergic amacrine cells and optic nerve myelination to prenatal endotoxin exposure. Invest Ophthalmol Vis Sci 2007; 48(1): 472-478.

60 Pike MG, Holmstrom G, de Vries LS, Pennock JM, Drew KJ, Sonksen PM et al. Patterns of visual impairment associated with lesions of the preterm brain. Dev Med Child Neurol 1994; 36: 849-862.

61 Harvey EM, Dobson V, Luna B, Scher MS. Grating acuity and visual-field development in children with intraventricular haemorrhage. Dev Med Child Neurol 1997; 39: 305-312.

62 Cusick M, Charles MK, Agron E, Sangiovanni JP, Ferris III FL, Charles S. Anatomical and visual results of vitreoretinal surgery for stage 5 retinopathy of prematurity. Retina 2006; 26(7): 729-735.

63 Leat SJ, Woo GC. The validity of current clinical tests of contrast sensitivity and their ability to predict reading speed in low vision. Eye 1997; 11(Part 6): 893-899. 
64 CRYO-ROP cooperative group. Contrast sensitivity at age 10 years in children who had threshold retinopathy of prematurity. Arch Ophthalmol 2001; 119: 1129-1133.

65 Larsson E, Rydberg A, Holmstrom G. Contrast sensitivity in 10 year old preterm and full term children: a population based study. $\mathrm{Br}$ J Ophthalmol 2006; 90(1): 87-90.

66 Dobson V, Quinn GE, Abramov I, Hardy RJ, Tung B, Siatkowski RM et al. Color vision measured with pseudoisochromatic plates at five-and-a-half years in eyes of children from the CRYO-ROP study. Invest Ophthalmol Vis Sci 1996; 37(12): 2467-2474.
67 Ospina LH, Lyons CJ, Matsuba C, Jan J, McCormick AQ. Argon laser photocoagulation for retinopathy of prematurity: long-term outcome. Eye 2005; 19(11): 1213-1218.

68 Enzenauer RW. Retinopathy of prematurity and weight of the baby's chart. J Am Acad Pediat Ophthalmol Strab 2001; 5: 198.

69 Holmstrom GE, Larsson EK. Development of spherical equivalent refraction in prematurely born children during the first 10 years of life: a population-based study. Arch Ophthalmol 2005; 123(10): 1404-1411.

70 Fledelius HC. Pre-term delivery and subsequent ocular development. 3 Refraction. Myopia of prematurity. Acta Ophthalmol Scand 1996; 74: 297-300. 